\title{
Rancang Bangun Prototipe Sistem Kontrol pH Tanah Untuk Tanaman Bawang Merah Menggunakan Sensor E201-C
}

\author{
Riry Djule Rima*, Wildian, Nini Firmawati \\ Laboratorium Elektronika dan Intrumentasi, Jurusan Fisika, \\ Fakultas Matematika dan Ilmu Pengetahuan Alam, Universitas Andalas \\ Kampus Unand Limau Manis, Padang, 25163, Indonesia \\ *rirydjulerima71@gmail.com
}

\begin{abstract}
ABSTRAK
Telah dilakukan rancang bangun prototype system kontrol $\mathrm{pH}$ tanah untuk tanaman bawang merah berbasis modul mikrokontroler Arduino Uno menggunakan sensor E201-C. Sensor E201-C mampu mendeteksi $\mathrm{pH}$ tanah dan data dari sensor diproses oleh mikrokontroler yang kemudian ditampilkan pada LCD. Sistem control on/off dengan menggunakan dua buah relai pada dua buah pompa air mini. Satu pompa digunakan untuk mengalirkan larutan daun ketapang dan pompa air lain digunakan untuk mengalirkan larutan kapur pada kotak yang ditanami bawang merah. Hasil uji system secara keseluruhan menunjukkan bahwa prototype system control ini sudah mampu mengontrol $\mathrm{pH}$ tanah yang diset pada $\mathrm{pH}$ 5,6-7. Bawang merah yang ditanam di dalam kotak yang dikontrol pHnya lebih baik pertumbuhannya dibandingkan dengan tanaman bawang merahyang ditanam di luar kotak.

Kata kunci : pH tanah, sensor E201-C, mikrokontroler, bawang merah, larutan daun ketapang, larutan kapur
\end{abstract}

\begin{abstract}
A design of ground pH control systemprototype for onion plant based on Arduino Uno microcontroller module using E201-C sensor have been conducted. The E201-C sensor is able to detect the soil pH and the data from the sensor is processed by the microcontroller which is then displayed on the LCD. Control system on / off using two relays on two mini water pumps. One pump is used to drain the ketapang leaf solution and another water pump is used to drain the lime solution on a box planted with red onion. Overall system test results show that the prototype of this control system able to control soil pH set at pH 5.6-7.Red onions grown in pH-controlled boxes are better for growth compared to onion crops planted outside the box.

Kata kunci :soil pH, sensor E201-C,microcontroler, red onion, leaf ketapang solution, lime solution
\end{abstract}

\section{PENDAHULUAN}

Tanah merupakan media alami yang diperlukan dalam kegiatan bercocok tanam. Tanaman akan tumbuh dengan baik apabilatanahnya subur. Beberapa hal yang mempengaruhi kesuburan tanah salah satu diantaranya adalah unsur hara.Banyak sedikitnya kandungan unsur hara pada tanah merupakan indikator tingkat kesuburan tanah yang akan mempengaruhi proses pertumbuhan dan perkembangan tanaman(Notohadiprawiro dkk,2006). Tingkat kesuburan tanah dipengaruhi oleh beberapa faktor salah satunya adalah derajat keasaman tanah ( $\mathrm{pH}$ tanah). Unsur hara akan mudah diserap tanaman pada $\mathrm{pH}$ 6-7, karena pada $\mathrm{pH}$ tersebut sebagian besar unsur hara akan larut dalam air (Martin, 2015).Keasaman tanah merupakan salah satu masalah utama bagi pertumbuhan tanaman. Tanah asam adalah tanah yang memiliki $\mathrm{pH}$ rendah yaitu kurang dari 6 . Tanah yang mengandung asam berlebih sering disebut dengan tanah gambut yang memiliki nilai $\mathrm{pH}$ 4-5. Tanah gambut banyak terdapat di Sumatera, salah satu diantaranya adalah daerah Riau. Pada tanah gambut tidak banyak tanaman yang bisa ditanami, hanya beberapa jenis tanaman seperti kelapa sawit dan nenas, namun sulit untuk ditanami sayursayuran sehingga Riau harus memasok sayuran dari daerah Sumatera Barat dan juga Jawa yang akan menambah biaya harian masyarakat sekitar(Riau.go.id, 2017).

Penelitian $\mathrm{pH}$ telah dilakukan oleh beberapa peneliti diantaranya Ihsanto (2014) melakukan rancang bangun alat untuk mengetahui derajat keasaman air menggunakan sensor $\mathrm{pH}$, Martin (2015) mengendalikan $\mathrm{pH}$ dan kelembaban tanah menggunakan soil moisture sensor dan sensor $\mathrm{pH}$, dan Arief (2017) untuk mengendalikan sistem $\mathrm{pH}$ yang terkandung di dalam air kolam ikan lele menggunakan sensor polymer optical fiber (POF) tipe SH-4001-1,3. Berdasarkan penelitian yang telah dilakukan beberapa peneliti di atas, hanya baru sebatas 
mengendalikan $\mathrm{pH}$ tanah menggunakan kapur dan air, perlu dirancang alat yang lebih terpadu yang dapat mengukur dan mengontrol $\mathrm{pH}$ tanah. Alat yang dirancang berupa sistem kendali secara otomatis yang berbasis mikrokontroler. Jenis tanaman yang akan dijadikan objek penelitian adalah bawang merah. Tanaman bawang merah memiliki $\mathrm{pH}$ 5,6-7 merupakan jenis tanah yang agak asam sampai normal. Tanah yang terlalu asam dengan $\mathrm{pH}$ di bawah 5,5 banyak mengandung garam aluminium $(\mathrm{Al})$. Garam ini bersifat racun sehingga dapat menyebabkan tanaman menjadi kerdil. Mikrokontroler yang mengontrol sistem keseluruhan berdasarkan data yang didapat dari sensor $\mathrm{pH}$ meter analog. Sensor $\mathrm{pH}$ yang digunakan adalah sensor elektroda E201-C.

Penelitian ini guna menaikkan $\mathrm{pH}$ tanah maka rangkaian relai bekerja secara otomatis untuk mengaktifkan pompa air kapur jika $\mathrm{pH}$ tanah lebih kecil dari $\mathrm{pH}$ normal tanah (5,6-7), penurunan $\mathrm{pH}$ tanah rangkaian relai bekerja secara otomatis untuk mengaktifkan pompa air rendaman daun ketapang jika $\mathrm{pH}$ tanah lebih besar dari $\mathrm{pH}$ normal tanah bawang merah.

\section{METODE}

\subsection{Alat dan Bahan}

Alat dan bahan yang digunakan dalam perancangan ini yaitu sensor $\mathrm{pH}$ E201-C, mikrokontroler Arduino Uno, LCD 2 x 16, multimeter, pompa air, $\mathrm{pH}$ meter, personal computer (PC), relai, dan bawang merah.

\subsection{Perancangan Diagram Blok Sistem}

Perancangan sistem kontrol $\mathrm{pH}$ tanah terdiri dari rangkaian sensor $\mathrm{pH}$ analog meter E201-C, rangkaian sistem minimum mikrokontroler, rangkaian LCD, dan rangkaian relai. Diagram blok dari perancangan sistem tersebut dapat dilihat pada Gambar 1.

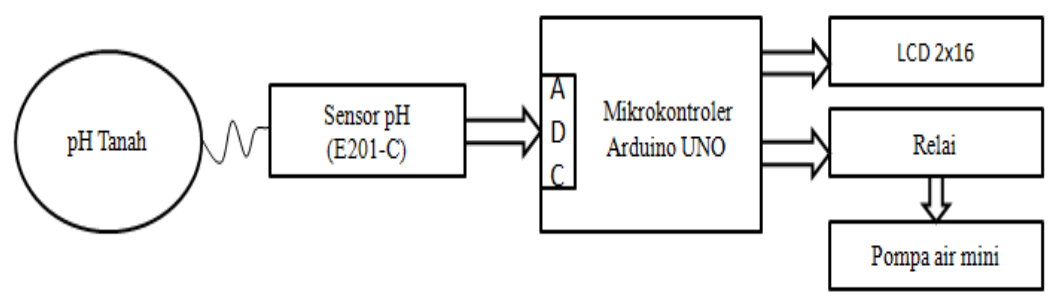

Gambar 1 Diagram Blok Sistem

\subsection{Perancangan Rangkaian Keseluruhan}

Sistem keseluruhan yang dibuat merupakan rangkaian yang digunakan agar sistem bekerja secara otomatis. Sistem otomatis ini menggunakan mikrokontroler Arduino Uno, sensor $\mathrm{pH}$, rangkaian relai dan rangkaian LCD 2x16. Penelitian memakai satu mikrokontroler untuk pengontrolan $\mathrm{pH}$ tanah. Skema rangkaian pengontrolan $\mathrm{pH}$ tanah dapat dilihat pada Gambar 2. 


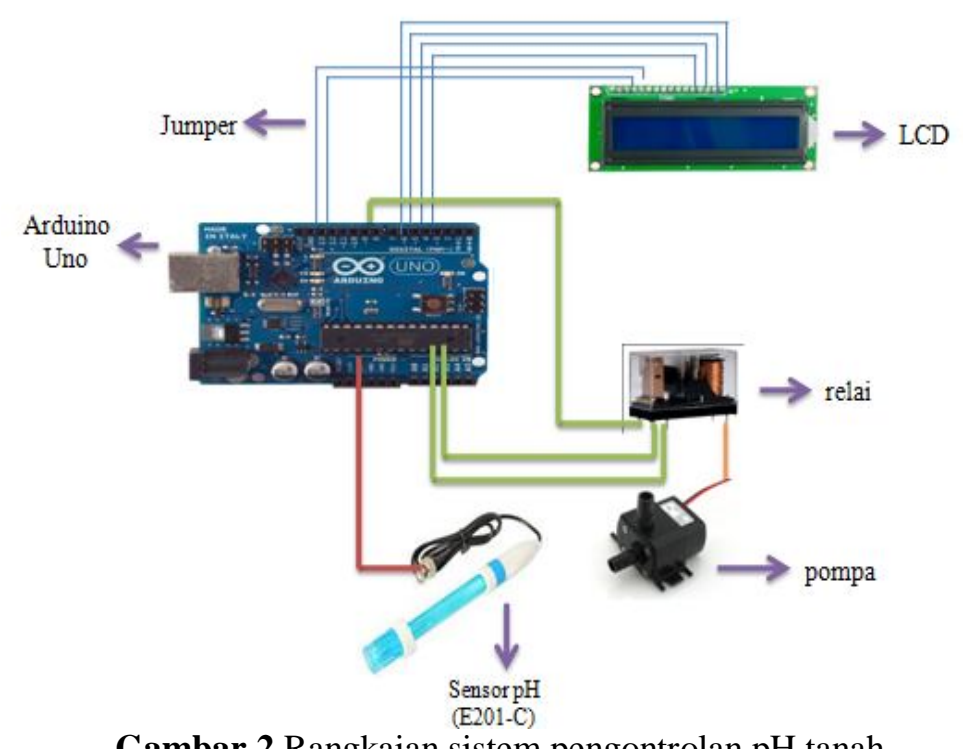

Gambar 2 Rangkaian sistem pengontrolan $\mathrm{pH}$ tanah

\subsection{Perancangan perangkat lunak}

Program pada mikrokontroler Arduino Uno dibuat dengan menggunakan bahasa C. Pada awal program, diberi input $\mathrm{pH}$ tanah, kemudian program membaca nilai $\mathrm{pH}$ tanah yang terdeteksi sensor $\mathrm{pH}$ E201-Cdi dalam tanah. Nilai input $\mathrm{pH}$ tanah yang terdeteksi dibandingkan, jika $\mathrm{pH}$ tanah yang terdeteksi lebih besar dari 7 maka pompa air larutan daun ketapang dihidupkan, jika $\mathrm{pH}$ terdeteksi lebih kecil 5,6 maka pompa larutan kapur yang hidup. Nilai $\mathrm{pH}$ yang terbaca akan ditampilkan pada LCD.

\section{HASIL DAN DISKUSI}

\subsection{Hasil Perancangan Alat}

Sistem kontrol pH tanah menggunakan larutan daun ketapang dan larutan kapur sebagai pengganti pupuk anorganik yang telah dibuat dapat dilihat pada Gambar 3. Perancangan sistem kontrol $\mathrm{pH}$ tanah ini terdiri dari rangkaian sistem minimum mikrokontroler Arduino Uno, LCD, 2 buah rangkaian relai, sensor $\mathrm{pH}$ E201-C, dan 2 buah pompa air.

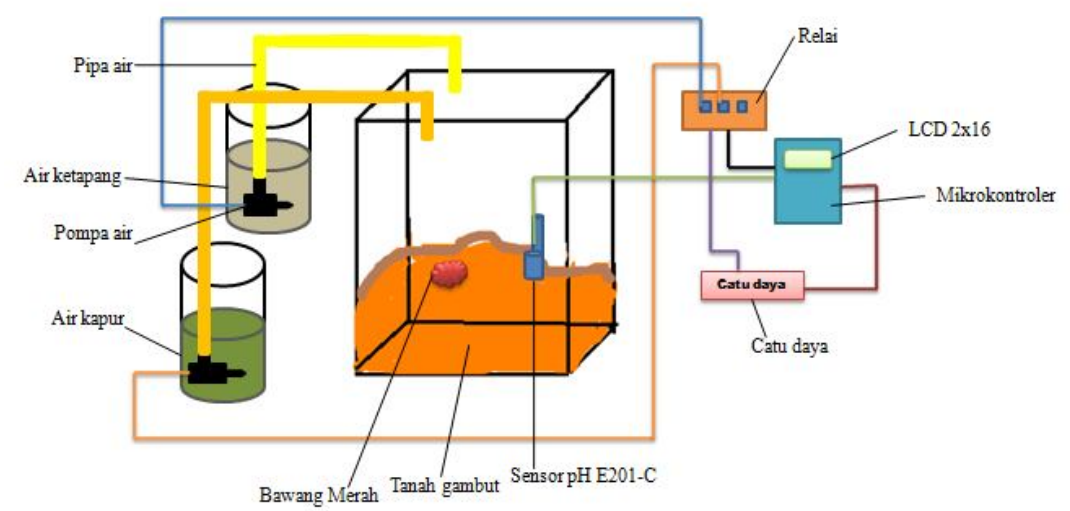

Gambar 3 Hasil rancangan alat

\subsection{Hasil Pengujian Rangkaian Sensor pH Tanah E201-C Pada PCB}

Pengujian sensor $\mathrm{pH}$ E201-C sebagai pendeteksi $\mathrm{pH}$ tanah dilakukan dengan membandingkan nilai $\mathrm{pH}$ menggunakan alat ukur $\mathrm{pH}$ meter dan tegangan keluaran yang dihasilkan oleh sensor $\mathrm{pH}$. Cairan yang digunakan untuk pengujian terdiri dari bermacam- 
macam larutan yaitu HCL, Asam asetat, Aquades, $\mathrm{NaOH}$, dan KOH. Grafik hubungan tegangan keluaran sensor E201-C dan pH Meter dapat dilihat pada Gambar 4.

Fungsi transfer dari hasil perbandingan antara tegangan keluaran sensor dengan nilai $\mathrm{pH}$ yaitu $\mathrm{y}=-0,184 \mathrm{x}+3,751$. Fungsi transfer ini menunjukan bahwa nilai sensitifitas sensor sebesar -0,184 dan memiliki tegangan offset sebesar 3,751 mV. Nilai koefisien deferminasi yang dihasilkan mendekati 1 yaitu sebesar 0,896. Nilai koefisien deferminasi ini menunjukkan bahwa tingkat kelinieran sensor sangat baik sehingga dapat digunakan sebagai alat ukur $\mathrm{pH}$.

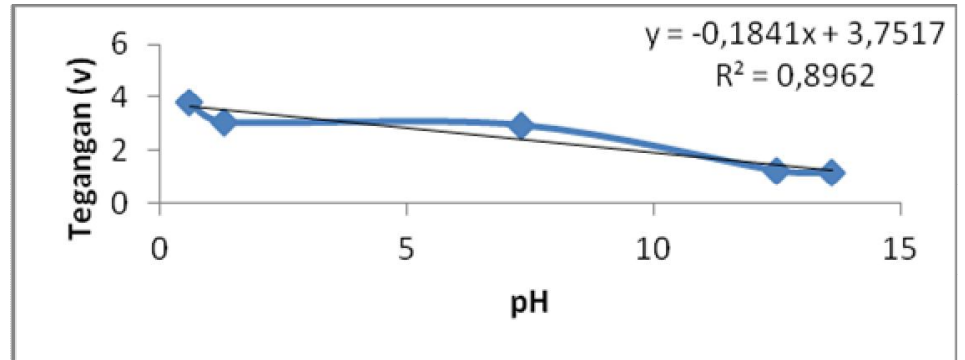

Gambar 4 Hubungan tegangan keluaran sensor $\mathrm{pH}$ dan $\mathrm{pH}$ meter

\subsection{Hasil Pengujian Rangkaian Relai}

Rangkaian relai berfungsi sebagai kontrol on/off dalam sistem kontrol $\mathrm{pH}$ tanah. Dalam penelitian ini dipakai dua buah relai untuk mematikan dan menghidupkan pompa larutan daun ketapang dan pompa larutan kapur. Pengujian rangkaian relai ini bertujuan untuk melihat apakah kedua relai dapat berfungsi dengan baik. Hasil pengujian rangkaian dapat dilihat pada Tabel 1. Jadi berdasarkan Tabel 1 didapatkan hasil bahwa rangkaian relai yang digunakan dalam penelitian ini berfungsi dengan baik dan dapat dilihat bahwa pompa bekerja sesuai $\mathrm{pH}$ yang telah diset yaitu jika $\mathrm{pH}$ di bawah 5,6 maka pompa 1 yang akan hidup dan jika $\mathrm{pH}$ di atas 7 maka pompa 2 yang akan hidup.

Tabel 1 Hasil pengujian relai pada kontrol $\mathrm{pH}$

\begin{tabular}{ccc}
\hline $\mathbf{p H}$ & Pompa 1 & Pompa 2 \\
\hline 2,19 & on & Off \\
2,20 & on & Off \\
2,98 & on & Off \\
3,29 & on & Off \\
3,47 & on & Off \\
7,03 & off & On \\
7,10 & off & On \\
7,29 & off & On \\
7,31 & off & On \\
7,80 & off & On \\
\hline
\end{tabular}

\subsection{Hasil Pengujian Aktuator}

Aktuator pada penelitian adalah 2 buah pompa air yang dikendalikan melalui 2 buah relai yang telah diprogram pada mikrokontroler. Pengujian kemampuan alat bertujuan untuk melihat kemampuan pompa air mengeluarkan masing-masing airnya yang sesuai dengan $\mathrm{pH}$ tanah. Hasil pengujian aktuator dapat dilihat pada Tabel 2.

Dari Tabel 2 dapat dilihat bahwa pompa air mengeluarkan larutan sesuai $\mathrm{pH}$ yang diinginkan yaitu jika $\mathrm{pH}$ tanah lebih kecil dari 5,6 maka pompa larutan air kapur akan hidup dan jika $\mathrm{pH}$ tanah lebih besar dari 7 maka pompa larutan daun ketapang akan hidup. Dari hasil pengujian kemampuan alat pompa air mengeluarkan larutan daun ketapang atau larutan kapur tersebut dapat dilihat bahwa pengujian aktuator berfungsi dengan baik. 
Tabel 2 Hasil pengujian aktuator pompa

\begin{tabular}{ccc}
\hline $\mathbf{p H}$ & $\begin{array}{c}\text { Pompa larutan Daun } \\
\text { ketapang }\end{array}$ & Pompa Larutan kapur \\
\hline 1,57 & off & On \\
1,97 & off & On \\
2,11 & off & On \\
2,30 & off & On \\
3,57 & off & On \\
7,18 & on & Off \\
7,40 & on & Off \\
7,63 & on & Off \\
7,80 & on & Off \\
7,92 & on & Off \\
\hline
\end{tabular}

\subsection{Hasil Pengujian Kemampuan Alat}

Hasil pengujian $\mathrm{pH}$ tanah untuk tanaman bawang merah dapat dilihat pada Tabel 3. Tabel 3 memperlihatkan perkembangan bawang merah selama 2 minggu penanaman di dalam dan di luar kotak. Berdasarkan Tabel 3 dapat dilihat pengukuran awal dari 10 buah bawang merah. Tanaman bawang merah di luar kotak ditanam 4 buah dan di dalam kotak ditanam 6 buah. Setelah penanaman selama 2 minggu bawang merah sudah mengalami pertambahan massa dan diameter juga akar yang sudah mulai terlihat.

Tanaman di luar kotak mengalami pertambahan massa rata-rata 39,75\% dan diameter rata-rata $52,5 \%$ juga akar yang sudah mulai terlihat. Tanaman di dalam kotak juga mengalami pertambahan massa rata-rata $79 \%$ dan diameter rata-rata $68,33 \%$ juga akar dan tunas yang sudah terlihat. Jadi dari penanaman tersebut dapat dilihat bahwa penanaman bawang merah di dalam kotak lebih baik pertumbuhannya dari pada penanaman bawang merah di luar kotak. Sehingga alat ini dapat dimanfaatkan petani untuk mengontrol $\mathrm{pH}$ tanah.

Tabel 3 Hasil pengukuran Bawang Merah

\begin{tabular}{|c|c|c|c|c|c|c|c|}
\hline \multirow[b]{2}{*}{ No } & \multicolumn{3}{|c|}{ Massa (g) } & \multicolumn{3}{|c|}{ Diameter $(\mathbf{c m})$} & \multirow[b]{2}{*}{ Sistem penanaman } \\
\hline & Awal & Akhir & $\begin{array}{c}\text { Selisih } \\
(\%)\end{array}$ & Awal & Akhir & $\begin{array}{c}\text { Selisih } \\
(\%)\end{array}$ & \\
\hline 1 & 6,47 & 6,74 & 27 & 6,5 & 6,7 & 20 & \multirow{4}{*}{$\begin{array}{l}\text { Dengan Sistem } \\
\text { pengontrolan } \mathrm{pH}\end{array}$} \\
\hline 2 & 5,18 & 5,73 & 55 & 5,5 & 6,0 & 50 & \\
\hline 3 & 4,18 & 4,44 & 26 & 5,0 & 5,5 & 50 & \\
\hline 4 & 5,26 & 5,77 & 51 & 5,5 & 6,4 & 90 & \\
\hline \multicolumn{3}{|c|}{ Presentase rata-rata } & 39,75 & & & 52,5 & \multirow{8}{*}{$\begin{array}{c}\text { Tanpa Sistem } \\
\text { pengontrolan } \mathrm{pH}\end{array}$} \\
\hline 5 & 4,93 & 5,21 & 28 & 6,2 & 6,5 & 30 & \\
\hline 6 & 5,19 & 5,59 & 40 & 6,5 & 6,7 & 20 & \\
\hline 7 & 2,85 & 3,39 & 54 & 5,2 & 5,4 & 20 & \\
\hline 8 & 3,73 & 4,96 & 123 & 5,0 & 6,5 & 150 & \\
\hline 9 & 3,39 & 4,54 & 115 & 5,3 & 6,8 & 150 & \\
\hline 10 & 5,69 & 6,83 & 114 & 6,0 & 6,4 & 40 & \\
\hline \multicolumn{3}{|c|}{ Presentase rata-rata } & 79 & & & 68,33 & \\
\hline
\end{tabular}

\section{KESIMPULAN}

Perancangan sistem kontrol $\mathrm{pH}$ tanah pada bawang merah menggunakan sensor E201-C sebagai sensor $\mathrm{pH}$ tanah serta larutan daun ketapang dan kapur sebagai pengontrol telah berhasil dilakukan. Perancangan alat ini berhasil mengontrol $\mathrm{pH}$ antara 5,6-7. Tanaman bawang merah di dalam kotak yang dikontrol pHnya lebih baik pertumbuhannya dari pada tanaman bawang merah di luar kotak. 


\section{DAFTAR PUSTAKA}

Arief, D, N., "Rancang Bangun Sistem Kontrol pH Air Pada Kolam Pembenihan Ikan Lele (Clarias gariepinus) Dibalai Pengembangan Teknologi kelautan dan Perikanan (BPTKP), Cangkringan, Sleman, Yogyakarta”, Jurnal Fisika, 6, 7-15 (2017).

Firmansyah, I, "Pertumbuhan dan Hasil Bawang Merah dengan Aplikasi Pupuk Organik Dan Pupuk Hayati Pada Tanah Alluvia, Jurnal Hort", 25, 133-141 (2015).

Ihsanto, E., "Rancang Bangun Sistem Pengukuran PH Meter Dengan Menggunakan Mikrokontrole Arduino Uno", Jurnal Teknik Eletro, 5, 139-146 (2014).

Martin, J., "Kendali pH dan Kelembaban Tanah Berbasis Logika Fuzzy Menggunakan Mikrokontroler", Jurnal E-proceeding of engineering, 2, 2236-2245 (2015).

Notohadiprawiro, T, Soekodarmodjo, S, Sukana, E.,"Pengelola Kesuburan Tanah dan Peningkatan Efisiensi Pemupukan", Ceramah Pada Pertemuan Ahli Teknologi, Pati, 2006.

Riau.go.id, 2013, Sumber Daya Alam, https://www.riau.go.id/home/content/66/sumber-dayaalam, diakses 15 Oktober 2017. 